\title{
INVESTED IN UNSUSTAINABILITY? ON THE PSYCHOSOCIAL PATTERNING OF ENGAGEMENT IN PRACTICES
}

CHRISTOPHER GROVES* (EMAIL: GROVESC1@CF.AC.UK), KAREN

HENWOOD*, FIONA SHIRANI* CATHERINE BUTLER ${ }^{\sharp}, K^{*}$ REN PARKHILL^, NICK PIDGEON*

* Cardiff University, Schools of Social Sciences and Psychology

\# University of Exeter, Geography Department

$\wedge$ University of York, Environment Department

\section{PRE-PUBLICATION ACCEPTED MANUSCRIPT FOR ENVIRONMENTAL}

\section{VALUES 2016}

To be cited as: Groves, C., Henwood, K., Shirani, F., Butler, C., Parkhill, K., and Pidgeon, N. (2016) Invested in unsustainability? On the psychosocial patterning of engagement in practices. Environmental Values. 24(6) 


\section{ABSTRACT}

Understanding how and why practices may be transformed is vital for any transition towards socio-environmental sustainability. However, theorising and explaining the role of individual agency in practice change continues to present challenges. In this paper we propose that theories of practice can be usefully combined with a psychosocial framework to explain how agency is biographically patterned and how this patterning is a product of attachment relationships and emergent strategies for dealing with uncertainty. Biographical interview data from the project Energy Biographies is used to illustrate the ways in which this theoretical approach can enhance understanding of how potential for practice change may be opened up or obstructed. KEYWORDS attachment, identity, narrative methods, practice theory, uncertainty 


\section{INTRODUCTION}

In attempting to understand the factors that will be important in shaping any transition towards socio-environmental sustainability, policy makers have often employed theoretical models of social change that assume individuals can be treated as rational choosers of behaviours. It follows from such ABC (attitude-behaviour-choice) models (Shove, 2010) that to achieve pro-environmental transitions will require effective communication of information about the costs and benefits of different choices, so as to promote change in consumption behaviour. However, such models have been heavily criticised for their reductive framings of agency as rationally-chosen action, alont with their failure to acknowledge the ways that materials, meanings and knowledge dynamically interact in constituting particular forms of practice (Uzzell, 2008; Shove, 2010). The sociological assumptions upon which they rest may thus be characterised as a questionable form of methodological individualism.

Social psychologists have responded by attempting to integrate in multiple factor models various additional elements - including values, beliefs and social norms (Stern, 2005). However, such approaches do not seek to understand the non-linear ways in which different elements, from technology and material infrastructure to broader societal values, can condition and produce each other in patterning (as contrasted with linearly causing) social change (Shove et al. 2012). Practice theory offers another approach, which is sociological rather than psychological in nature. It identifies practices as patterned and purposive shared activities that change over time (Shove and Pantzar 2005) and which help explain why individuals hold particular beliefs and values, but also why they act in particular ways (Shove et al. 2012; Hards, 2011).

Shove et al. (2012) have produced a recent and influential account of practice theory, drawing on theoretical work by Reckwitz (2002) and Schatzki (1996) amongst others. In their account, practices comprise three elements which can change over time: competences, materials and meanings. They are reproduced with variations through time across performances by collections of individual actors. How exactly the agency of subjects is linked to practices, however, remains a complex question that requires further exploration. Shove et al.'s theory draws our attention to how practices 'recruit' and 'retain' the loyalty of individuals, and how collections of practices constitute distinctive environments (e.g. obesogenic, envirogenic) that pattern activity in 
particular ways, and shape subjectivities accordingly (Shove 2010). It has, however, mainly done this by looking at how individual agency is shaped and constrained, over time, by the emergence of particular sets of practices. This form of practice theory therefore stresses that understanding change requires an understanding of the biographies of practices (Maller and Strengers, 2013).

In this paper, we draw on selections from data generated as part of a social science research project, Energy Biographies, in arguing that social settings, as productive of inter-subjectivity, should be understood as including other elements that are not addressed concretely through practice theories. These other elements are attachments or investments which are a product of biographical experiences and which are, themselves, patterned in and across time (Finn and Henwood, 2009; Coltart and Henwood, 2012). The contribution of such relational elements to agency lies in how they affect the individual's ontological security in the face of an intrinsically uncertain future (Giddens, 1991; Henwood and Pidgeon, 2013), by influencing how people make sense of the world around them either as reliable and trustworthy or as insecure and untrustworthy. These sense-making activities condition active agency, understood as individual and collective strategies for dealing with uncertainty. Following Marris (1996), we identify this emphasis on attachment and uncertainty as opening up a psycho-social route, distinct from practice theory though related to it, through which individual biographies may be linked to wider socio-cultural patterns of meaning and agency.

Within our data, we identify ways in which recruitment to and defection from specific practices may be influenced by biographical patterns of attachment, and particularly changes or disruptions in the patterning of individual experiences, investments and subjectivities. Concepts of attachment and their constitutive value for identity (Yates and Day Sclater, 2000), we propose, should thus be considered as significant psychosocial analytical complements to practice theory, which allow us to understand how biographical experiences may hold wider significance for the ways in which people act in the world (Hollway et al. 2003; Hollway, 1989). Exploring such experiences may allow us to understand how, for example, some practices (including unsustainable ones) retain participants' loyalty while others suffer defections. This is not to resurrect some form of methodological individualism, such as that which underlies the rational actor 
model of subjectivity at the heart of the ABC approach. Instead, a psychosocial approach works with a concept of complex subjectivity and intersubjectivity that is inseparable from a dynamic condition of affectively and emotionally-patterned embodiment.

\section{THEORISING CHANGE: PRACTICE THEORY, TRANSFORMATIVE MOMENTS AND} ATTACHMENT

Practice theorists often conceptualise social change in terms of innovation in, recruitment to or defection from practices on the part of individuals (Shove et al. 2012; Reckwitz, 2002; Schatzski, 1996). These processes are related, in turn, to transformations in the elements that constitute practices (which Shove et al. condense into competences, meanings and materials). Such transformations may be dependent on wider social change in infrastructures, competences and/or meanings, or may arise as a result of the creativity of collections of performers. Both of these possibilities are explored by Shove et al., (2012) as ways of understanding changes in practices, in the values of individuals, and in which practices they participate. Other have suggested another avenue of investigation, one in which biographical transitions are identified as significant parts of the environment that shape changes in participation in practices and therefore in values (e.g. Hards, 2011; 2012; Butler et al. 2014a).

For Hards (2011) this includes the proposition that practice theory contains the possibility of a dialogue between agent-focused and meso-level theories of social change. She attempts to promote such a dialogue with two concepts. First, the idea of communities of practice, a concept which originates with Lave and Wenger (1991), in which individually-transformative social interactions arise between participants involved in shared practices. Second, the idea of transformative moments - that is, epiphanic, emotionally-intense experiences which trigger, as part of initiation into or participation in communities of practice, shifts in practices and in values. The narrative interviews in Hards' study of individuals engaged in pro-environmental lifestyles show, she suggests, that people interpret major changes in the practices in which they engage as resulting from such moments $(2011,2012)$.

These moments are not represented by interviewees as brought about by new information or knowledge about the world. Instead, they are interpreted as rooted in long-standing beliefs in which individuals are intensely emotionally invested, or to 
emotionally-intense experiences which expose deeper truths of some kind. They are therefore path-dependent to a significant degree, as they build on earlier biographical developments (Hards, 2012), and may be associated with performing specific practices; with particular lifecourse transitions; with certain sorts of contextual experience featuring particularly intense sensory or emotional components; and/or with particular kinds of interaction with others (2011: 37). Transformative moments are thus taken to be indicators of the existence of what Hards, following Shove's usage, calls envirogenic contexts, i.e. ones that encourage particular kinds of pro-environmental engagement, but also point to the influence of patterns of individual experience and their effects on emotional commitments to particular competences or meanings.

Narratives of lived experience may assist us in exploring the significance of transformative episodes for individuals, in which they defect from or come to engage in practices. But if we wish to explore this hypothesis, there remain the questions of how these episodes arise, to what patterning influences they are subject and to what extent these may fall outside practice theory's conceptual framework. Why individuals engage in or defect from practices has been argued to be related to the internal rewards of engaging in them (Shove et al. 2012). Drawing on Alasdair MacIntyre's (1981) work, they argue that performing a practice according to shared understandings of what it is to 'do it well' brings satisfaction and meaning. However, Hards' analysis suggests that engaging in practices also bring another reward: they can be constitutive of identity and support valued forms of identity in the face of change.

If biographical transitions reflect individual emotional experiences, then these experiences may be rooted in long-standing developmental patterns of psychological adjustment to social circumstances such as are explored in objects-relations theory, which deals with how the emergence and character of subjectivity depends on the dynamics of relationships that develop between the subject and its others throughout childhood and adolescence. It is true that the shaping of subjectivity as a process influenced by practices has, as noted above, been explored by practice theory. It has, for example, long recognised what Schatzki $(1996,93)$ calls 'identity-bestowing understandings of action'. Part of practices, Schatzki suggests, are teleoaffective structures, which contain what are taken to be 'correct or acceptable' purposes, projects, 'emotions, feelings, and passions' (Schatzki 1996, 124). Shove, Pantzar and 
Watson (2012, 23-4) note that the status of such future-oriented and future-disclosing structures is contentious within practice theory, and opt to identify them with 'meaning' more generally. Reckwitz is firm on this issue, however, asserting that ' $[\mathrm{w}] \mathrm{ants}$ and emotions ... do not belong to individuals but - in the form of knowledge - to practices' (Reckwitz 2002, 254).

If teleoaffective structures, as future-oriented structures of feeling, mood and emotion with roots in the past, are at bottom elements of practices and not properties of individuals, however, then this does not account for another source of such structures: specific relationships in which individuals are heavily emotionally invested, and how, as a result of such relationships, individuals learn to handle social relationships more generally (whether emotionally significant or not). The concept of attachments meanings rooted in biographical patterns of emotional connection - provides a way of thinking about how relationships contribute to knowledge, agency and identity. It can also assist us in understanding how individuals value (and engage in or defect from) practices.

The internal rewards of practices (which practice theory conceptualises as inducing engagement or defection) may be thought of as related to how individuals - conceived, as in object-relations theory, as complex, always connected, relational subjects - find in these practices modes of being and doing that support their sense of who they are, but also of how they should 'handle' others to whom they are connected, or with whom they come into contact. Practices are not just structures, third-person explanatory variables; they matter to subjects (Sayer 2011) precisely because they help create expectations, produce feelings of autonomy by encouraging mastery of competences and reinforce connection with others through shared meanings. And the ways in which they play such roles in relation to an internally complex, psychosocial subject may help us understand how practices may change - a concern central to any desired transition towards socioenvironmental sustainability.

\section{ENERGY BIOGRAPHIES: RESEARCH METHODS AND APPROACH}

In the following sections, we draw on Energy Biographies data to explore how the roles played in the evolution of practices by forms of complex (inter)subjectivity such as those mapped in the previous section may be understood. Energy Biographies employs 
repeat narrative interviews alongside multimodal methods to examine energy usage and sustainable practices more widely in the context of biographical transitions. This approach allows us to explore how attachment and strategies for dealing with it pattern participation in practices. Narrative elicitation enables interviewees to explore the affective and emotional content of biographical transitions, unlike more structured qualitative approaches. In addition, they allow researchers to explore the complex connections between transformative moments and the attachments that constitute the 'what matters' (Sayer 2011) of individual lives. This gives the added advantage of encouraging interviewees to explore connections between values and practices in the light of present events, past changes and future possibilities (Henwood and Shirani, 2012a).

Across four diverse case site areas in the UK, interviews were conducted with individuals on three occasions over a one year period. In total, 74 people participated in first round interviews. A sub-sample of 36, selected for gender balance and to represent a range of demographic and socio-economic profiles, as well as different experiences of transition, took part in the two subsequent rounds of interviews, along with multimodal activities. In the analysis we draw on extracts from a small number of interviews to illustrate key points, but the overall argument, readings of theory and emergent conclusions are arrived at through an iterative process of engagement with data and theory informed by the dataset at a whole.

Our analysis below identifies from the data four research topics connected to transformations in practice where a psychosocial approach to attachment may complement approaches set out by practice theorists, and develops key elements of a suitable conceptual framework alongside a reading of our data. These topics are: 1) what the rewards of participating in practices might be; 2) how attachment contributes to the temporal organisation of subjectivity; 3 ) how the disruption of practices may undermine attachments; and 4) how different styles of handling attachment produce active strategies for taming uncertainty.

\section{1. 'We know it's bad but we're still going to use it': relational rewards and the meaning of} practice 
Defection from or continuing to participate in practices, as Shove et al. (2012) point out, may be seen as conditioned by the meaning of practices in two ways. First, practices are, by definition, associated with goods or 'rewards' internal to them. Achieving these goods by engaging in the practice defines what it is to perform the practice well. Second, the meaning of practices is shaped by whether engaging in them reproduces shared symbolic distinctions (like good/bad, pure/impure) that are significant to the individual. These factors may explain why individuals go on from first encounters with a practice to become loyal participants (Shove, et al. 2012: 66-7, 74-75). In both cases, practices help to produce identity: they contribute to individuals' sense of who they are within social settings, and what they can accomplish within them. They thus take on constitutive value (O’Neill, 1993) for the individual, as internal ingredients of identity. However, internal rewards and external linkages may not be entirely transparent to individuals. Some rewards may be experienced by the individual as a source of shame or guilt, or may be unavailable to the individual because his or her sense of identity and/or self-efficacy depends on denying particular motivations and/or desires.

For example, beginning to participate in a practice such as bicycle commuting may, by providing new competences and encouraging emotional investment in the meanings associated with the practice (such as sustainability, efficiency, health and so on), bolster the individual's sense of identity and self-efficacy. These rewards may both encourage recruitment to a practice and motivate continued participation. However, some rewards associated with the practice may be less acknowledged, perhaps because they are negative or defensive in nature. For example, commuting by bicycle may provide an outlet for aggression through 'masculinized' risk-taking urban cycling (Balkmar, 2009) and may re-inscribe, through such ways of performing the practice, social distinctions (subcultural in this case) between autonomous individuals ('real' cyclists who are able to cycle fast and confidently in traffic) and dependent ones (less confident bicycle users who may prefer to cycle on pavements) (Aldred, 2012).

Loyalty to practices (such as to road cycling among cyclists who self-identify as autonomous) may lead to resistance to change (such as the creation of more dedicated cycling infrastructure) born of anxiety or fear at the potential destabilisation of the self (as perhaps manifested in campaigns among cyclists about losing the 'right to the road'). Understanding recruitment to a practice may therefore require psychosocially 
sensitised approaches, in order to investigate what phenomena such as defensiveness, evasion (Hoggett, 2013) or humour (Parkhill et al., 2011) within talk about practices may signify about subjective responses to change. Conversely, defection from practices may be a product of anger or disgust, a rejection of a certain image of the self or desire for another identity. Without being sensitised to such dimensions of participation in practices, it may be difficult to understand what secures individuals as participants, and how emotional investments may prevent or encourage participation, defection or indeed practice innovation.

The meaning of attachments may therefore be seen as an element of the internal rewards of practices, but as simultaneously related to and different from the shared meanings of practices. They arise as part of biographical experiences of attachment relationships through which individual identity is formed. At the same time, they are inseparable from experiences of practices which do have shared meanings (such as the autonomy that may be identified with road cycling). But the individual's connection to the practice is shaped by his or her own psychosocial biography, and his or her methods of handling attachment relationships with others and the vulnerabilities that arise from them. As we shall see in Section 3.4 below, these methods are not themselves strictly individual. They reflect more widely shared 'structures of feeling' (Hoggett and Thompson 2012) that produce collective strategies for dealing with uncertainty. Nonetheless, attachments should be treated as analytically distinct from practices in considering how practice participation becomes patterned over time. This point echoes arguments regarding the links between biography and shared meanings made elsewhere in psychosocial literature (e.g. Jefferson, 1996).

We now turn to extracts from Energy Biographies interviews with Lucy to demonstrate how participation in particular practices is not simply about instrumental outcomes but relates centrally to attachments and rewards connected to these. When Lucy was first interviewed she had recently moved from London with her partner and young children to a house in an affluent commuter village on the outskirts of Cardiff. Lucy and her husband both had family roots in South Wales. This move to an area where they had family connections was bound up with the desire for an ideal home and for an enhanced quality of life. This entailed establishing a (re)new(ed) identity, centring on their new rural surroundings and the possibilities for hosting family and old friends from London 
afforded by their new home. Where new energy-using practices emerge here they are associated with attachments that are integral to this identity-building process.

As part of a photography task during the project, Lucy took pictures of patio heaters, which she recognised as 'wasteful' and 'bad' but also as vital, in a specific sense. Her sense of their wastefulness jars with her belief that, generally speaking, she runs an energy efficient household. Importantly, though, she downplays the wastefulness of 'heating the outdoors' (Hitchings, 2007) because a particular vision of how one should enjoy rural life is important to her:

we do love our patio heater when it's a sunny evening but it gets a bit cold and dark and you can sit out and they're like probably the worst things aren't they? But we love it well we only use it about five times a year so it's OK.

Her description of why the practice of heating the outdoors matters to her derives from a shared meaning of the practice - i.e., the way in which it provides a degree of control over the uncertain British weather so as to maximise opportunities to enjoy being outside (Hitchens, 2007). But the precise meaning of this added control, for Lucy, lies partly in the internal rewards of the practice, which derive in turn from how it contributes to her identity of the generous hostess in her new home, and also to the renewed meaning of her friendships:

Cos we love being outside, we just love that you can you know go, we were sitting out there one evening ... it was like midnight and you could have a drink outside still and it's so lovely here cos it's so quiet and everything so but you wouldn't have been able to do it without that so or you would have been freezing. So that's our kind of, we know it's really bad but we're still going to use it.

The rewards of participation in practices are therefore not purely instrumental in the conventional sense (one engages in $x$ to obtain or earn $y$ ). If participation is constitutive of continuing emotional investment, one of its payoffs is in constituting and confirming the identity of the individual 'I am the type of individual who does $x$ '. Such investments, and what happens to them, are ingredients of an individual's evaluations of how s/he takes his/her life to be going (Sayer, 2011). They are the kind of goods which may be 
taken to be a constitutive (rather than instrumental) part of human flourishing, and what happens to them affects whether a human life goes well or badly (O'Neill, 1993). To understand engagement in practices as part of lived experience, it is therefore necessary to understand, as Sayer (2011) argues, experience as structured by a concern both for oneself and one's emotional investments. Lucy's re-building of her sense of herself as hostess through participation in practices such as heating the outdoors confirms her wish that the family's quality of life be enhanced as a result of their move. It is also symbolic of how, in this new context, she is able to sustain long-established and important attachments to friends as part of her readjusted identity.

This example of Lucy's participation in specific unsustainable energy-using practices underlines that to understand why people engage in practices means it is necessary to understand their relationality (Groenhout, 2004; Butler et al. 2014b). The meanings, competences and material of shared practices are one element of this relationality. But a biographical approach to practices underlines that attachment relationships and how they are constitutive of identity are still another element. What practices people engage in is influenced by how they evaluate things to be going for those things and people that matter to them. These evaluations in turn shape their view of what kind of person they are. Sense-making is closely bound up with practice, but also with emotional connectedness, a consideration that is as manifest in a desire for flexibility or disconnection as it is in a desire for solidarity or intimacy (Benjamin, 1990: 169-170). Practices have internal rewards, but some of these are relational rewards, payoffs shaped by the meaning of attachment relationships.

From birth, object-relations theory suggests, experiences of attachment are ones through which anticipations and expectations of needs-satisfaction are created. Through such experiences, it becomes possible for the subject to domesticate troubling affects, such as rage, anxiety, or panic. Emotional self-regulation is perhaps the most important contribution of attachment in infancy (Stern, 1985). Emotions have definite objects, and may be treated as intentional, embodied judgements about the world (Nussbaum, 2001) around which the identity of the self is integrated. Emotions provide one way of making sense of affects, giving them both meaning and direction (see Hollway and Jefferson, 1997) and shaping individuals' sense of identity but also their self-efficacy, the sense of being able to meaningfully influence their environment. 
The degree to which emotional regulation is possible for an individual shapes how they manage relationships with others - through secure attachment, avoidance, ambivalence or disorganisation (see e.g. Bretherton, 1992). Through this developmental process, the world is constituted for the subject as a more or less 'secure space' within which it is possible to act in different ways. Between child and world, the secure (or in D.W. Winnicott's terminology, transitional), space is thus a field of emotional possibilities for the domestication of affect. It takes on different qualities depending on individuals' characteristic attachment styles (e.g. favouring intimate connection or a tendency to withdraw and be alone), with consequences for how identity and self-efficacy are patterned. In this sense, it is biographical in a way that marks it as analytically distinct from Schatzki's practice-dependent teleoaffective structures. ${ }^{1}$ Insecure attachment can result in emotional complexes of paralysis and aggression as ways of dealing with persistent anxiety. 'Good enough' attachment, on the other hand, assures the child that experimenting with the world will not destroy either its integrity or that of the self (Benjamin, 1990: 46).

Other extensions of object-relations approaches suggest that the contribution made by patterns of attachment to domesticating an intrinsically uncertain future is not limited to relationships with caregivers. As the individual passes through childhood and into adolescence, then adulthood, attachments and the secure space that emerges around them expand to incorporate circles of transitional objects (Young, 1989), which may include places (Twigger-Ross and Uzzell, 1996), cultural objects (Lewis, 1969), institutions, practices and, ultimately, the ideals and guiding values enshrined in shared cultural narratives, and which express interpretations of how connectedness should be managed or lived (Marris, 1996). Collections of such objects of attachment extend the individual's secure space to embrace the socio-natural environments s/he inhabits, linking the individual to the past and future outlined in cultural narratives through which a broader, metaphysical sense of how things should be is made possible (Rappaport, 1996). The secure, or transitional space is, in the work of D.W. Winnicott, neither fully inside the isolated individual nor located in shared, public space. Instead, it is constituted from ambiguous transitional objects that are partially submerged in the

\footnotetext{
${ }^{1}$ It is also therefore distinct from Bourdieu's concept of habitus, which designates sets of practical, cognitive and emotional dispositions or readinesses-to-act in particular ways that come from 'training' individuals in a wide range of practices in particular social settings (Lizardo 2004).
} 
external world while also protruding into the 'inside' of identity and self-efficacy (Jones, 1991).

These theoretical insights can be related back to what we might identify as Lucy's secure space. It is evident that her sense of who she is and her feelings of self-efficacy are bound up with her relationships to family and friends, and to place, which together constitute an emotional and symbolic space in which the unsustainable practice she engages in plays a nonetheless identity-sustaining role. In particular, it plays a part in helping consolidate the meaning of established relationships in a new context, folding a still unsettled everyday life back into her secure space. In this function, we find the private and biographically-shaped 'relational reward' that the practice offers her.

\section{2. 'It's always been there': attachment, insecurity, and the temporal organisation of subjectivity}

To understand more precisely what is implied by the constitutive value of participating in practices, we now turn to consider more closely the ways in which our data illuminates how the connection between practices and attachment helps to domesticate an intrinsically uncertain future. A concern with the uncertainty of the future is one that is as close to universally human as we can get, and one which is as symbolic and emotional in nature as it is also concerned with the affordances of material reality (Jackson, 1989: 15-16).

This function of attachment has already been seen at work in Lucy's biographical transition to her new home. We move now to another, more explicit, example of how attachments to practices can help domesticate uncertainty, even while individuals undergo transitions that bring insecurity and vulnerability with them. Attachment, as we saw in the previous section, contributes to the temporal organisation of subjectivity. The anticipations and expectations that are dependent on it allow the subject to deal with uncertainties relating to external events. In three interviews Sarah recounts three different job transitions in London and links her feelings about employment, in each case, to whether her workplace affords her an opportunity to cycle to work. Cycling is something that for Sarah has connections to her memories of childhood in Ireland before she and her mother moved to London. Her continuing participation in cycling now is connected to those memories. 
So I cycle there and back ... when my daughter was young I had a seat on the back for her and cycled as much as I could ... It's just quicker to get to work, it's so much quicker ... So it was convenience as well and obviously I wanted to try and get fit and yes, it just seemed like, they've introduced an underground sort of cage where you use your pass to get in. So it's quite a secure bike lock up. So once I knew they had that I was more inclined to ... And my mum always cycled when I was young, I always remember being on the back of her bike in Dublin. So yes, and when we lived in the countryside in Ireland, I cycled to school two miles each way because there were no buses. So yes, it's just something that's always been there.

Cycling has practical advantages related to commuting: 'you know how long it's going to take you ... generally speaking and you just feel healthier'. In one sense, then, its value derives from the practical ways in which it can reduce uncertainty. Sarah feels its deeper value lies, however, in how it connects her to her environment (in particular, to her own neighbourhood and to the north London community nearby where her mother lives and in which she used to live when they first moved to London), and also in how it connects home to workplace. She is particularly conscious of how her previous job facilitated this, and how her latest move has undermined it.

I cycled to Hampstead yeah in my old job which was a lot nicer because you cycle through Hampstead Heath but here it's Central London, it's Euston, it's really really busy and I'm quite scared about because we don't have decent cycle lanes at all. So just have to be really careful.

This example demonstrates, again, how attachment to a practice is about more than the rewards that engaging in the practice as an object of shared meanings can provide. Cycling is accepted by many cyclists (and non-cyclists) to be a more convenient and efficient way of getting around in the city than driving. It is also widely seen as a sustainable form of transport. But the rewards of cycling for Sarah are connected to more private emotional meanings which relate to how she negotiates issues related to identity and self-efficacy, along with her ability to manage her time and to navigate her environment. These meanings are rooted in an expanded secure space in which her work place is tangibly linked to a biographical narrative, at the heart of which is the 
north London community she enjoyed living in when younger and where her mother still lives: it has 'a village atmosphere and people are friendly'

\section{3. 'It will be a loss': disrupted practices and broken attachments}

Sarah's experience of moving jobs has created a situation where the practice of cycling, her evaluation of which is shaped by her biographically-conditioned identity and sense of self-efficacy, has become difficult for her. This raises questions as to what effect the biographical disruption of practices may have on attachment, or vice versa.

Attachments may motivate recruitment to practices. Practices, in turn, may create additional attachments. Changes to the elements of practices may disrupt attachments, however, and conversely, disruption of attachments may lead on to defection from practices. Practices, Shove et al. (2012: 3) state, are what allow us to 'go on' in social life. Research on attachment however suggests that, when attachments are displaced or broken, it may be the case that we cannot 'go on': 'we no longer know what to do' (Marris, 1996: 3). Damaged attachments may erode both identity and self-efficacy (Marris, 1991: 77), effects which may only be overcome through a lengthy reintegration of the self and a re-evaluation of other attachments and 'what matters' to the individual in general (Nussbaum, 2001). If attachment helps human beings live with the vulnerability to which they are exposed by an inherently uncertain future, then the breaking of attachment re-exposes them to this vulnerability.

A further example from our data that illustrates some aspects of these connections between practice, attachment disruption and loss is provided by Ronald, an affluent village resident in his seventies. Attachment to driving - and indeed a particular kind of driving - appears, for Ronald, to be a central part of his identity, centring on specific cars as material objects that bear the traces of ongoing care, particular competences, and shared meanings. At the core of his relationship with driving is a kind of autonomy connected with the experience of controlled risk, and a sense of comradeship that revolves around building, modifying and driving cars.

I would have no wish to rally in a modern in a modern car, whichever engine it was propelled by, no wish at all. It would be quite good fun to drive balls out in the most recent Mini, just to see what it was like through a forest, I would enjoy 
that yes please! ... but that would be a novelty; it wouldn't be what turns me on. What turns me on is a piece of old kit that you've put together and you've developed and, you know, the cars I have are not just reconstructed but I've developed them as you would have developed them from original. They are not an original but they do stuff that they couldn't do when they were first built.... That's the appeal for me; you've done this, you've put it together, you and your chum, its adventure, more than motorsport in a sense ... the adventure bit is every much as important as the mechanical bit but both are important ... so I wouldn't want to do that in a battery-powered car or a hydrogen car or a modern car, wouldn't want to do it and it wouldn't turn me on.

Ronald is, however, also very conscious of a variety of issues relating to sustainability, and in particular, issues relating to resource and particularly oil depletion. A future without plentiful petroleum, where these events may no longer be possible, is one in which his identity would be threatened. 'I feel it will be a loss for certainly my generation and probably for the generation behind me. I think it will be a loss'. An imagined future in which the material infrastructure on which Ronald's preferred style of driving depends is degraded is one in which he finds it hard to picture a place for the competences, ideals and forms of friendship that he identifies as central to his identity. Driving may continue thanks to the development of new infrastructures (e.g. for electric cars), but not in a way that can support either the shared meanings or adventure associated with Ronald's preferred style of driving, or the personal, internal rewards of risk-related autonomy that he finds to be central to participating. The depth of the prospective loss he anticipates is underlined both by how he repeats words through which he admits a sense of inevitability ('it will be a loss'), and the way he imaginatively extends his perspective to encompass the attachment to leisure driving he believes characterises multiple generations of drivers.

\section{4. 'I think we're all a bit obsessed': attachment and strategies for dealing with uncertainty}

Experiences of attachment loss or even anticipations thereof are, as we have seen, experiences of resurgent vulnerability. Such encounters may be dealt with in differing ways, depending on biography. More or less intense processes of grieving following 
attachment loss (Nussbaum, 2001) may be lived and experienced very differently by individuals whose emotional relationships are characterised by a secure style of attachment, than individuals who manifest an avoidant/dismissive style, or an avoidant/fearful one (Worden, 2008: 69-70). Patterns of attachment explored, as in previous sections, through narrative interviewing and other elicitation methods sensitised, through a psychosocial lens, to the 'unsaid', can show how attachment styles are mirrored by strategic orientations towards dealing with uncertainty that render it liveable, despite the difficulties it brings.

For example, disconnected styles of attachment developed in relation to painful experiences of loss and/or vulnerability may orient the individual towards a defensive strategy towards uncertainty, which allows subjects to maintain their identity and selfefficacy by extracting forms of autonomy from within difficult experiences of vulnerability and dependence (Gilligan, 1982). Such strategic orientations are not without their own difficulties. At the extreme, defensive strategies may shade into withdrawal from attachment (Marris, 1996), mirroring the avoidant/fearful attachment styles identified by developmental psychologists.

Participation in practices may therefore be motivated not just by particular attachments, but by particular 'styles' of attachment, patterns which develop biographically out of experiences of vulnerability. Though we have stressed so far the importance of biographical patterns of individual attachment in understanding participation in or defection from practices, we have noted that focusing on attachment may also provide us with another way of understanding shared aspects of practice. If the meaning of practices for individuals is related to their attachments and to the styles of attachment they develop over time, it is also connected to shared meanings related to styles of attachment (as contrasted with shared meanings of practices), insofar as these styles are manifest as shared socio-cultural phenomena. As authors such as Moglen (2005) suggest, how vulnerability is dealt with can have effects that extend far beyond the emotional life of individuals.

Fullilove (2004) and Erikson (1995), for example, have documented how disruption to attachment and to practice often results from accidents, disasters or large-scale intentional social change, e.g. slum clearance. Patterned responses, over time, to attachment loss and to vulnerability occasioned through attachment are therefore often 
not just individual strategies for dealing with uncertainty. They can also, as Marris (1996) argues, represent collective strategies for taming an uncertain future, based on shared experiences. Here, the internal rewards of practice are not simply idiosyncratic, but meet attachment needs experienced by individuals in similar ways within smaller or larger groups. One of the side-effects of these strategies, however, is to redistribute uncertainty, which may impose additional burdens on some actors and also create unintended consequences, some of which may undermine a given strategy itself in the longer term (Marris, 1996). The unspoken rewards of practice may therefore include particular ways of handling vulnerability which promote culturally-prevalent or dominant forms of identity via, for example, assurances of autonomy, invulnerability and so on. These rewards may be valued even where the strategies that produce them may turn out eventually to be self-undermining (as in the case of valued consumption practices that are extremely expensive or environmentally unsustainable, for example).

An example of how such consequences may emerge from practices that 'speak to' widely shared experiences of vulnerability is suggested by Lucy, while describing the importance of her freezer.

I think they're necessary but I think we're all a bit obsessed, like I think when people have two freezers like my mother-in-law has a chest freezer and she doesn't know what half the stuff in there is and I was talking about this with a friend and they said they cleared out their grandmother's freezer once with her and there were things that had been in there for like eight years that she's like made and dated ... I think it also results in a way of wasting more food because you go oh I'll just shove it in the freezer but actually you never end up using it or you end up chucking it out because it's been in there too long or whatever so. I think it's a necessary thing that we've taken, we've become a bit over the top obsessed with you know.

The freezer has been described by practice theorists as a 'time machine', around which are organised a variety of practices (Shove and Southerton, 2000), thanks to the appliance's significance for managing conflicting time pressures (enabling last-minute meal preparation for those who work long hours, etc.). In relation to the theme of strategically managing uncertainty, this instrumental value of the freezer seems relevant. However, Lucy's example suggests that freezing also has constitutive value in 
relation to identity, self-efficacy and the secure space of individuals. For example, the obsession with freezing is one, Lucy suggests, with accumulating food. This ordinarily unsaid value may be read as a way of establishing a feeling of security for the household and family through stockpiling.

The previous generations referenced by Lucy well have known times of hardship and scarcity in earlier life. The emotional and symbolic significance of the freezer and freezing may then be related to escaping this early biographical phase of identity and its negative associations. Lucy's talk about her freezer implicitly acknowledges the practice-theoretical point that the freezer and its material networks enrol individuals in particular practices, such as batch cooking with quick meals for young children in mind. At the same time, however, the emotional significance of participating in these practices relates to identity ('good enough' parenting and mothering), associated ideals (plentiful food, home-cooking), the vulnerable interiority of the household (food stored against contingencies) and even ideals of sustainability (avoiding consumption of heavily packaged ready meals, allowing preservation of home-grown food). The 'obsession' Lucy mentions evokes a strategy of seeking security through particular practices, but one which has its own defensive and inherently unsustainable dynamic that itself generates uncertainty - in the form of increasing waste and the higher levels of energy use necessary to maintain full freezers.

\section{CONCLUSION}

This paper has responded to practice theory by elaborating a psychosocial approach to studying practice change. This approach helps us to understand how attachment ('why things matter to people', in Sayer's terms) may influence participation in practices whether these are sustainable (e.g. cycling) or unsustainable (e.g. heating the outdoors). The contribution of practices to maintaining biographical and/or socio-culturally shared patterns of emotional investment provides relational rewards for individuals and groups engaged in particular practices.

We have thus shown that the meaning of practices is broader but also deeper than is typically explicated through many forms of practice theory. By focusing on the links between practice and attachment, the rewards of practices can be understood as, in part, their contributions to building and rebuilding identities and a secure space in the 
face of uncertainty. Further, the attraction of individuals to particular practices may be shaped by styles or patterns of attachment which evolve in relation to experiences of connection but also of vulnerability and loss. Finally, these patterns are not just individual. They can express wider patterns of attachment which embody shared strategies for dealing with uncertainty that may, in turn, have significant unintended consequences. In alerting us to these dimensions of the significance of practice, attachment theory does not therefore, as has been claimed, simply depict subjectivity as centred upon a constant search for an 'antidote to fear and anxiety' (Miller, 2008: 60). On the contrary, it helps us understand how different ways of handling attachment create specific forms of agency and shape perspectives on what is desirable and rational.

By developing this analytical framework through analysis of the qualitative data gathered by the Energy Biographies project, we have shown how it opens up new possibilities for exploring the ways in which efforts at changing practices, as part of a transition towards sustainability, need to pay heed not just to what practices are available and normalised in a community, but also to how participation in these practices is affected by individual and shared patterns of attachment. Not only can attachment (to place, for example) encourage participation in more sustainable practices, as part of an identity. It can also drive participation in practices (like driving inefficient cars or heating the outdoors) which are manifestly unsustainable and which can exist in tension with other commitments and shared meanings (e.g. Lucy's views on not wasting energy, and her recognition that patio heaters are widely seen as 'bad'). The perspective we have developed here thus deepens, from a policy perspective, critiques of $\mathrm{ABC}$ approaches to sustainable transitions, by posing the question of how the 'unsaid' supports the persistence of unsustainable practices. This issue is already recognised by some psycho-socially informed approaches to changing individual and community practices and attitudes relevant to climate change, such as Carbon Conversations (Randall 2009), for example. In this example, individual and group conversations are used to ventilate dilemmas and unspoken fears relating to climate change, along with how it connects to the ways in which energy is used in everyday life. The goal of these interventions is to drive change in practices by confronting their relationship to aspects of valued identities that individuals may otherwise find hard to acknowledge. 
In addition to these implications, two research questions related to sustainable transitions and energy practices arise out of our work. On the one hand, the framework introduced in this paper opens up the possibility of connecting practice-theoretical approaches to psychosocial work relating to lifecourse transitions (McQueen and Henwood, 2002), and exploring further the utility of narrative (Henwood and Coltart, 2012) and linked elicitation and analysis methods (Henwood and Shirani, 2012b) for exploring the meaning and structure of these transitions. On the other, the link between emotional investments/attachments, identity and shared meanings, identified by psychosocial researchers (Hollway and Jefferson, 2005; Jefferson, 1996; Segal, 1990) and some sociologists (Marris, 1996), requires further exploration. In particular, additional theoretical resources may help us to examine this link in relation to narrative biographical data. How are lifecourse transitions themselves socially patterned, and how do these patterns ameliorate or exacerbate disruptions to practice and attachment in the life of the individual and/or of the group?

\section{ACKNOWLEDGEMENTS}

This research was funded by the UK Economic and Social Research Council [grant number RES-628-25-0028]. The authors would like to thank three anonymous referees for helpful comments.

\section{REFERENCES}

Aldred, R. 2012. 'Incompetent or Too Competent? Negotiating Everyday Cycling Identities in a Motor Dominated Society.' Mobilities 8(2): 252-271.

http://dx.doi.org/10.1080/17450101.2012.696342

Balkmar, D. 2009. 'Spinning around the "lycra lout"', in B. Ney and A. Beyene (eds), Centrum med många riktningar - en vänbok till Gunilla Bjerén Stockhom: Stockhom University. pp. 11-24.

Benjamin, J. 1990. The Bonds of Love. London: Virago.

Bretherton, I. 1992. 'The origins of attachment theory: John Bowlby and Mary Ainsworth'. Developmental Psychology 28(5): 759-775. 
http://dx.doi.org/10.1037/0012-1649.28.5.759

Butler, C., K. A. Parkhill, F. Shirani and K. Henwood. 2014a. 'Exploring the Dynamics of Energy Demand through a Biographical Lens'. Nature and Culture 9(2): 164 -182.

http://dx.doi.org/10.3167/nc.2014.090204

Butler, C., K.A. Parkhill and N. Pidgeon. 2014b. 'Energy Consumption and Everyday Life: Choice, values and agency through a practice theoretical lens', Journal of Consumer Culture 19.

http://dx.doi.org/10.1177/1469540514553691

Coltart, C. and K. Henwood. 2012. 'On paternal subjectivity: a qualitative longitudinal and psychosocial case analysis of men's classed positions and transitions to first-time fatherhood'. Qualitative Research 12(1): 35-52.

http://dx.doi.org/10.1177/1468794111426224

Erikson, K. 1995. A New Species of Trouble. New York, W.W. Norton.

Finn, M. and K. Henwood. 2009. 'Exploring masculinities within men’s identificatory imaginings of first-time fatherhood'. British Journal of Social Psychology 48(3): 547-562. http://dx.doi.org/10.1348/014466608X386099

Fullilove, M.T. 2004. Root Shock. New York: Ballantine.

Giddens, A. 1991. Modernity and Self-Identity. Palo Alto, CA: Stanford University Press. Gilligan, C. 1982. In a Different Voice. Cambridge, MA: Harvard University Press.

Groenhout, R.E. 2004. Connected Lives. Lanham, MD: Rowman \& Littlefield.

Hards, S. 2011. 'Social Practice and the Evolution of Personal Environmental Values'. Environmental Values 20(1): 23-42.

http://dx.doi.org/10.3197/096327111X12922350165996

Hards, S. 2012. 'Tales of transformation: The potential of a narrative approach to proenvironmental practices'. Geoforum 43(4): 760-771.

http://dx.doi.org/10.1016/j.geoforum.2012.01.004 
Henwood, K. and K. Coltart. 2012. 'Researching lives through time: Analytics, narrative and the psychosocial', in B. Neale and K. Henwood (eds), A Timescapes Methods Guide, No. 10. Online at: http://www.timescapes.leeds.ac.uk/resources/publications Henwood, K.L. and N.F. Pidgeon. 2013. Future Identities: Changing Identities in the UKthe Next 10 Years: DR 17. London: Government Office for Science.

Henwood, K. and F. Shirani. 2012a. 'Researching the temporal', in H. Cooper, P.M. Camic, D.L. Long et al. (eds), APA Handbook of Research Methods in Psychology, Vol 2: Research Designs: Quantitative, Qualitative, Neuropsychological, and Biological. Washington, DC: American Psychological Association. pp. 209-223.

http://dx.doi.org/10.1037/13620-013

Henwood, K. and F. Shirani. 2012b. 'Extending temporal horizons', in B. Neale and K. Henwood (eds), A Timescapes Methods Guide, No. 4. Online at:

http://www.timescapes.leeds.ac.uk/resources/publications

Hitchings, R. 2007. 'Geographies of embodied outdoor experience and the arrival of the patio heater'. Area 39(3): 340-348.

http://dx.doi.org/10.1111/j.1475-4762.2007.00754.x

Hoggett, P. 2013. 'Climate Change in a Perverse Culture', in S. Weintrobe (ed.), Engaging with Climate Change. Hove: Routledge. pp. 56-71.

Hoggett, P. and S. Thompson. 2012. 'Introduction', in P. Hoggett and S. Thompson (eds), Politics and the Emotions: The Affective Turn in Contemporary Political Studies. London: Continuum International Publishing. pp. 1-20.

Hollway, W. and T. Jefferson. 1997. 'The Risk Society in an Age of Anxiety: Situating Fear of Crime'. The British Journal of Sociology 48(2): 255-266.

http://dx.doi.org/10.2307/591751

Hollway, W. and T. Jefferson. 2005. 'Panic and perjury: A psychosocial exploration of agency'. British Journal of Social Psychology 44(2): 147-164.

http://dx.doi.org/10.1348/014466604X18983

Hollway, W., C. Venn, V. Walkerdine, J. Henriques and C. Urwin (eds). 2003. Changing the Subject: Psychology, Social Regulation and Subjectivity. $2^{\text {nd }}$ edn. London: Routledge. 
Jackson, M. 1989. Paths Toward a Clearing: Radical Empiricism and Ethnographic Inquiry. Bloomington, IN: Indiana University Press.

Jefferson, T. 1996. 'From "little fairy boy" to "the compleat destroyer": subjectivity and transformation in the biography of Mike Tyson', in M. Mac an Ghaill (ed.), Understanding Masculinities: Social Relations and Cultural Arenas. Buckingham: OU Press. pp. 153-167. Jones, J.W. 1991. 'The Relational Self: Contemporary Psychoanalysis Reconsiders Religion'. Journal of the American Academy of Religion 59(1): 119-135.

http://dx.doi.org/10.1093/jaarel/LIX.1.119

Lave, J. and E. Wenger. 1991. Situated Learning: Legitimate Peripheral Participation. Cambridge: Cambridge University Press.

http://dx.doi.org/10.1017/CB09780511815355

Lewis, 0. 1969. 'The possessions of the poor'. Scientific American 221: 114-124. http://dx.doi.org/10.1038/scientificamerican1069-114

Lizardo, 0. 2004. 'The Cognitive Origins of Bourdieu's Habitus'. Journal for the Theory of Social Behaviour 34(4): 375-401.

http://dx.doi.org/10.1111/j.1468-5914.2004.00255.xMacintyre, A. 1981. After Virtue: $a$ Study in Moral Theory. London: Duckworth.

Maller, C. and Y. Strengers. 2013. 'The global migration of everyday life: Investigating the practice memories of Australian migrants'. Geoforum 44: 243-252.

http://dx.doi.org/10.1016/j.geoforum.2012.09.002

Marris, P. 1991. 'The social construction of uncertainty', in C.M. Parkes, J. StevensonHinde and P. Marris (eds), Attachment across the Life Cycle. London: Routledge. pp. 7790.

Marris, P. 1996. The Politics of Uncertainty: Attachment in Private and Public Life. London; New York: Routledge. http://dx.doi.org/10.4324/9780203360293

McQueen, C. and K.L. Henwood. 2002. 'Young men in "crisis": Attending to the language of teenage boys' distress'. Social Science and Medicine 55: 1493-1509.

http://dx.doi.org/10.1016/S0277-9536(01)00186-1 
Miller, G. 2008. 'Why Scottish personal relations theory matters politically'. Scottish Affairs 62: 47-62.

http://dx.doi.org/10.3366/scot.2008.0003

Moglen, S. 2005. 'Mourning social injury'. Psychoanalysis, Culture \& Society 10: 151-167. http://dx.doi.org/10.1057/palgrave.pcs.2100032

Nussbaum, M.C. 2001. Upheavals of Thought: the Intelligence of Emotions. Cambridge: Cambridge University Press.

http://dx.doi.org/10.1017/CB09780511840715

O'Neill, J. 1993. Ecology, Policy and Politics. London, Routledge. http://dx.doi.org/10.4324/9780203416570

Parkhill, K.A., K.L. Henwood, N.F. Pidgeon and P. Simmons. 2011. 'Laughing it off? Humour, affect and emotion work in communities living with nuclear risk'. The British Journal of Sociology 62(2): 324-346.

http://dx.doi.org/10.1111/j.1468-4446.2011.01367.x

Randall, R. 2009. 'Loss and Climate Change: The Cost of Parallel Narratives'. Ecopsychology 1(3): 118-129.

http://dx.doi.org/10.1089/eco.2009.0034

Rappaport, R.A.1996. 'Risk and the human environment'. Annals of the American Academy of Political and Social Science 545: 64-74.

http://dx.doi.org/10.1177/0002716296545001007

Reckwitz, A. 2002. 'Toward a Theory of Social Practices: A Development in Culturalist Theorizing'. European Journal of Social Theory 5(2): 243-263.

http://dx.doi.org/10.1177/13684310222225432

Sayer, A. 2011. Why Things Matter to People: Social Science, Values and Ethical Life. Cambridge; New York: Cambridge University Press.

http://dx.doi.org/10.1017/CB09780511734779

Schatzki, T.R. 1996. Social Practices: A Wittgensteinian Approach to Human Activity and the Social. Cambridge: Cambridge University Press. 
http://dx.doi.org/10.1017/CB09780511527470

Segal, L. 1990. Slow Motion, Changing Masculinities, Changing Men. London: Virago Press

Shove, E. 2010. 'Beyond the ABC: climate change policy and theories of social change'. Environment and Planning A 42(6): 1273-1285.

http://dx.doi.org/10.1068/a42282

Shove, E. and M. Pantzar. 2005. 'Fossilisation'. Ethnologia Europaea 35(1-2): 59-63.

Shove, E., M. Pantzar and M. Watson. 2012. The Dynamics of Social Practice: Everyday Life and how it Changes. London: SAGE Publications.

http://dx.doi.org/10.4135/9781446250655.n1

Shove, E. and D. Southerton. 2000. 'Defrosting the Freezer: From Novelty to

Convenience: A Narrative of Normalization'. Journal of Material Culture 5(3): 301-319.

http://dx.doi.org/10.1177/135918350000500303

Stern, D.N. 1985. The Interpersonal World of the Infant : a View from Psychoanalysis and Developmental Psychology. New York: Basic Books.

Stern, P.C. 2005. 'Understanding individuals' environmentally significant behavior'. Environmental Law Reporter News and Analysis 35(11): 10785-10790.

Twigger-Ross, C.L. and D.L. Uzzell. 1996. 'Place and identity processes'. Journal of Environmental Psychology 16(3): 205-220.

http://dx.doi.org/10.1006/jevp.1996.0017

Uzzell, D. 2008. The challenge of climate change: the challenge for psychology.

Australian Psychological Association Annual Conference. Hobart, Tasmania.

Worden, J.W. 2008. Grief Counseling and Grief Therapy, fourth edition. New York: Springer.

Yates, C. and S. Day Sclater. 2000. 'Culture, Psychology and Transitional Space', in C. Squire (ed.), Culture and Psychology. London: Routledge. pp. 133-146.

http://dx.doi.org/10.4324/9780203361047_chapter_9 
Young, R.M. 1989. 'Transitional phenomena', in B. Richards (ed.), Crises of the Self:

Further Essays on Psychoanalysis and Politics. London: Free Association Books. pp. 5772. 